\title{
Passive Cooling Of Houses by Placing the Municipality Running Water Installation inside the Walls
}

\author{
Stojan Rendevski, Mohammed Abdulrahman Almansoori, \\ Abdullah Hamad Mohamed Ali Alsherwe \\ Faculty of Engineering and Technology, Higher Colleges of Technology, Ras al Khaimah Men's Campus, \\ United Arab Emirates
}

\begin{abstract}
Low energy consumption for cooling houses/buildings is of great importance for countries in wide geographical and climate regions in the world (including UAE), when thinking on energy saving, supporting the economy growth and environmental protection. The main objective of the research is to show that this can be achieved by constructing the water pipes installation in houses/buildings to go through two walls in every room. In a lot of geographical/climate regions, incoming water is cold enough (bellow $22-24^{\circ} \mathrm{C}$ ). A model house $1 \mathrm{~m} x$ $1 \mathrm{~m}$ has been constructed with similar materials to the real. Temperature-power-time dependence in the space has been monitored by thermocouples. Elements of Building Physics and Heat Transport Physics has been used to validate the efficiency of the model. The cost-benefit analysis (costs of pipes and fittings, additional equipment, labor hours) is in favor of the benefit of the proposed idea.
\end{abstract}

Keywords: passive cooling, municipality water, energy saving

\section{Introduction}

Passive cooling of houses and buildings can be defined in several different ways. One way is to consider any treatment of the building which reduces its cooling load, such as solar control, minimizing internal heat gain, lowering the urban temperatures, shading of windows, and envelope's exterior colors (facades) of low solar absorptivity. Another way is to consider all the above-mentioned topics as elements of proper architectural and urban design, responsive to the climate and aiming to improve thermal comfort in hot periods even when the building is not mechanically conditioned, or to lower the equipment size and energy consumption in air-conditioned buildings. Passive cooling of buildings from this viewpoint comes after appropriate design has been applied, and can be defined as the use of renewable sources of energy to enhance heat loss from the building.

The goal of passive systems of cooling is to lower the indoor temperatures to comfortable level. A higher air speed in a building extends the upper limit of the comfort zone, beyond the limit for still air conditions, and may provide a direct physiological cooling effect. Such higher indoor air speed may result from opening the windows or by operating ceiling and other small fans. The desirability of a higher air speed occurs often during the daytime hours. Therefore, daytime ventilation can be defined also as direct comfort ventilation, especially in cases when it also lowers the indoor temperatures, when the indoor temperature in unventilated buildings is higher than the outdoor air temperature due to solar and/or internal heat gain. Recent experimental studies in Thailand and in Singapore have demonstrated that an indoor air speed of 2-3 m/s can extend the upper comfort temperature, of persons acclimatizes to the hot humid climate, well above the conventional limits. While at still air the "comfort temperature" was about $27.5^{\circ} \mathrm{C}$, with air speed of $2 \mathrm{~m} / \mathrm{s}$ the comfort temperature was about $34{ }^{\circ} \mathrm{C}[1]$.

Any surface which "sees" the sky loses heat by the emission of longwave radiation toward the sky, and can be regarded as a heat radiator. Although the radiant heat loss takes place day and night, only during the nights the radiant balance is negative, because sun doesn't have an input at night. During the daytime, the absorbed solar radiation counteracts the cooling effect of the longwave emission and produces a net radiant heat gain. The main problems with radiant cooling are the transfer of the cooling effect to the interior of the building and the prolonged storage of the "cold" generated at night for lowering the indoor daytime temperatures. Roofs are usually insulated, to minimize heat loss in winter and heat gain in summer. As the radiant loss takes place at the external surface of the roof the insulation minimizes the actual cooling that a building can utilize from the nocturnal radiation, unless specialized designs (radiant cooling systems) are applied. The radiant cooling uses the roof as the "cold collector". In this system, the (horizontal) roof is made of structural steel deck plates. Thermal mass is provided by large plastic bags filled with water are placed over the metal roof deck, above a black sheet. Above the water bags there are movable insulation panels that can be moved by a motor. The insulation panels can be moved over an adjacent parking area or a balcony, thus exposing the water bags. In summer, when cooling is needed, the water bags are exposed during the night hours, and cooled by longwave radiation to the sky. The cooled water bags are in direct thermal contact with the metal deck and thus the ceiling serves as a cooling element over the whole space below. During the daytime hours, the insulation panels are 
moved over the water bags, thus shading and insulating them. In winter the bags are exposed to the sun during the day and covered by the insulation panels during the nights, and the system then serves as a passive solar heating system. The effectiveness of nocturnal cooling depends on the diurnal temperature swing. Therefore, it is mainly applicable in regions with diurnal swings of more than about $8{ }^{0} \mathrm{C}$, mainly in hot dry climates. In regions with small diurnal swings, such as many hot humid areas, night cooling cannot improve the sleeping comfort of the occupants at significant level [2].

When we speak about passive cooling of houses and buildings, energy savings that can be achieved are the main parameter for simple analysis of the efficiency, together with the cost-benefit analysis. The investment in passive cooling, in our case, investment in more water plastic pipes with all the fittings, additional parts and the extra working hours during construction, should be rational from the economical point of view. It is common to think that any investment in passive cooling that can return money spent after five years of operation (time under energy savings) is worth and appreciated. Energy saving is important parameter to follow on any passive cooling systems, such as the proposed "Passive cooling of houses/buildings by placing the running water installation inside the walls". If the energy savings in units of $\mathrm{kW} \cdot \mathrm{h}$ are only percent of the total energy spent on air conditioning, we cannot talk about energy efficient system of cooling. It is common to think on a system as energy efficient if it can save more than $50 \%$ of the total energy spent on electricity for air conditioning [3].

Municipality water that comes to every household or commercial site is already running and we pay for consumption. We pay the same if same volume of water is going out directly from all the taps, baths, garden hoses, kitchen sink, etc., same as we pay if same volume of water previously is going through water installation pipes inside the walls and then out of taps, baths, etc. Municipality water that goes underground is always colder than the ambient air temperature above the ground. The temperature difference depends on the climate and geographical region. In UAE, during summer we found average temperature of urban water underground at 25 ${ }^{0} \mathrm{C}$ and at winter $19-20{ }^{\circ} \mathrm{C}$. This is more than necessary to use the municipality water as a cooling agent when the average ambient temperatures are $33{ }^{\circ} \mathrm{C}$ in summer, $25{ }^{\circ} \mathrm{C}$ and $30{ }^{\circ} \mathrm{C}$ in spring and autumn. In winter, the proposed method of passive cooling is not effective (average ambient temperature of $21{ }^{0} \mathrm{C}$ ) and the water comes at $19{ }^{\circ} \mathrm{C}$, but in general there is no need of cooling in winter, because we want average temperature of the comfort of $23{ }^{0} \mathrm{C}$, not $21{ }^{0} \mathrm{C}$ as it is outside. Passive cooling systems based on using the municipality water running through installation inside the walls of houses or buildings has not been investigated or applied in great extent, if at any. One study in Turkey proved it worth in time when the prices of plastic water pipes and tubes were lower [4]. The drop of the prices of the plastic water pipes and tubes should make us to think on considering the proposed method of cooling in any geographical region and under various climate conditions.

Providing comfortable indoor living conditions when outdoor temperature is high can be very problematic. The most effective method to cool a building is to avoid heating. The basic source of heat in a building is the sunlight energy absorbed through the roof, walls, windows as well as the heat generated by appliances and air leakages. Although, there are some specific methods to prevent the accumulation of heat, adopting all those strategies might not be possible or adequate. Air-conditioning provides some relief. However, its initial costs as well as the related costs of electricity consumption make the technology expensive. In addition, conventional air-conditioners use refrigerants made of chlorine compounds which are involved in the ozone layer depletion and global warming. It is noteworthy that human production of greenhouse gases, especially $\mathrm{CO}_{2}$, is changing the global climate. Statistics show that nearly $50 \%$ of $\mathrm{CO}_{2}$ emissions in developed countries are derived from energy consumption in the buildings [5]. Thus, it is obvious that the well-controlled and energy-efficient ventilation systems are prerequisite for low-energy-consumption as well as a substantial reduction in $\mathrm{CO}_{2}$ emissions. Employing natural or passive cooling system can be an alternative way to maintain a cool house or reduce air-conditioning load. A passive cooling system employs non-mechanical procedures to maintain suitable indoor temperature. Ingenuity of ancient architectures has showed how a rational use of traditional passive techniques, along with a smart design, was involved in having desired summer comfort without a need to pursue mechanical cooling systems. Recently, there is much inclination toward these systems, especially due to economic and environmental reasons. The low-energy passive technique of ventilation can provide thermal needs of occupants in the buildings.

The solar energy and an evaporative cooling technique can be used simultaneously. Many researches have been conducted on using natural ventilation and evaporative cooling for producing cool air so far. One idea lies in capturing the wind within a wind tower and then passing it through wetted conduit walls or underground channel [6].

The underground channel enhances the tower efficiency in cooling the input air as a result of increasing evaporation. Obviously, each factor raising the evaporation from the channel's walls into the air, enhances the air cooling and system efficiency. Therefore, the channel is constructed near the garden at a depth of around 5-7 $\mathrm{m}$ below ground level to increase the humidity of the channel [7]. Thus, the used water to irrigate the garden is applied to cool the house as well. Since the gardens were irrigated once or twice a week, the channel's wall surface is almost always damp that caused more air cooling. In fact, the channel is a kind of Earth to air heat 
exchanger (EAHE) in which the underground air duct is made of brick. The air is cooled not only by means of temperature gradient between outdoor air and the earth but also by humidification process. Construction is one of the most important significant economic sectors worldwide and represents a global world's annual close to $\$ 3$ trillion [8]. This corresponds almost to $10 \%$ of the global economy. However, more than one billion of people live in squats, slums and inappropriate houses, while in many cities in the less developed world between one to two third of the population live in overcrowded poor quality houses. Buildings present a very high energy consumption compared to the other economic sectors. Although percentages vary from country to country, buildings are responsible for about $30-45 \%$ of the global energy demand. As a result of the application of very intensive energy savings' measures and technologies, the thermal performance of buildings during the winter period has been tremendously improved mainly in the developed world. On the contrary, because of the increasing standards of life, the affordability of air conditioning, the universalization of modern architecture and also the temperature increase in the urban environment and the global climatic change, the energy needs for cooling have increased in a rather dramatic way. Heat island has a very serious impact on the energy consumption for cooling purposes. Heat island is the most documented phenomenon of climatic change and increases highly urban temperatures. Furthermore, the phenomenon increases the cooling energy consumption of buildings and the peak electricity demand, intensify the thermal stress in urban areas, worsen air quality as the rate of photochemical ozone production is accelerated because of the higher urban temperatures, and increases considerably the ecological footprint of cities. In parallel, as heat island is mainly presented in dense populated areas, it has a serious impact on indoor comfort conditions in low income housing and increases considerably the energy needs to achieve basic comfort conditions in summer. Global climatic change has also a serious impact on the energy consumption of the buildings sector for cooling purposes. Recent research has shown that because of the expected serious future temperature increase, the energy demand of the buildings sector in Greece could decrease by about 50\% while the corresponding energy consumption for cooling could increase by $248 \%$ until 2100 [9]. The serious penetration of air conditioning has an important impact on the absolute energy consumption of buildings. Studies have shown that refrigeration and air conditioning are responsible for about $15 \%$ of the total electricity consumption in the world, while in Europe air conditioning increases in average the total energy consumption of commercial buildings to about $40 \mathrm{kWh} / \mathrm{m}^{2} / \mathrm{y}$. Apart of the energy systems, air conditioning may be an important source of indoor air quality problems. Condensate trays and cooling coils may be contaminated by organic dust. This may cause fungal and mold growth in fans. Also, dirty filters may cause important contamination problems, while cooling towers may cause spread of Legionellae disease [5, 10]. It is well known that the temperature of the ground at a depth of about 2.5 to $3 \mathrm{~m}$ remains fairly constant and low around the year. The idea to dissipate the excess heat from a building to a natural sink like the ground is known from the ancient time. The most common technique to couple buildings and other structures with the ground is the use of underground air tunnels, known as earth-to-air-heatexchangers (EATHE). Earth to air heat exchangers consist of pipes which are buried in the soil while an air circulation system forces the air through the pipes and eventually mixes it with the indoor air of the building or the agricultural greenhouse. The performance of the EATHE system varies as a function of its characteristics such as the length and the diameter of the pipe, the air flow rate, the depth where the system is buried, the thermal characteristics of the soil, the pipes' material, etc. Hundreds of studies have been performed in order to develop models able to predict the efficiency of the earth to air heat exchangers, to analyze the experimental performance of pilot applications and to report the global performance of real scale case studies. At the initial stage of the research many problems associated to the use of ground pipes were reported. Most of them dealt with the accumulation of water inside the tubes, problems of indoor air quality, lack of efficient and dynamic control during the operation, etc. However, recent applications have overcome efficiently the initial barriers and given the quality and the quantity of the available actual knowledge and information, it may be concluded that EATHE is a very mature and quite efficient technology. Studies have shown that for moderate climates the seasonal energy performance of the EATHE systems is close to $8-10 \mathrm{kWh} / \mathrm{m}^{2}$ of ground coupling area, while the peak cooling capacity at air temperature close to $32{ }^{\circ} \mathrm{C}$ is estimated at $45 \mathrm{~W} / \mathrm{m}^{2}$ of ground coupling area [10].

Radiant cooling is an alternative option for passive cooling since it has energy and peak power saving potentials. In Europe, it is reported that cooling tower could be used to cool the water for supply to the radiant panel on the ceiling. This is considered a passive cooling option and has even higher potential for energy and peak power saving. When radiant cooling is used with displacement ventilation, where ventilation air is introduced at low level and flows by natural means to replace ventilation air, such system has been suggested to offer quiet comfort and energy efficiency superior to those of conventional air-conditioning systems. In Europe, cooling water at temperature between $18{ }^{\circ} \mathrm{C}$ and $20{ }^{\circ} \mathrm{C}$ is used to supply to the panel [11]. Such temperatures would not lead to condensation of moisture from air, but offers opportunity for substantial energy savings since water of such temperatures could be provided without resort to refrigeration or active cooling. Heat transfer rates between 25 and $75 \mathrm{~W} / \mathrm{m}^{2}$ at panel surface could also be achieved [12]. To employ radiant cooling in hot and humid climate, it is considered a challenge. To avoid condensation of moisture from air on the panel, the 
temperature of cooling water must not be lower than dew-point temperature of air [13]. To achieve thermal comfort, the temperature of air in the space should not reach $30{ }^{\circ} \mathrm{C}$. This condition offers a real challenge. Our strategy is to consider application of radiant cooling to households during night-time first, and then considers other means to help achieve thermal comfort when radiant cooling is applied during daytime. In the application of radiant cooling in hot and humid climate, we perceive that it would be necessary to avoid condensation of moisture from the air on the radiant panel, in our case, on the water installation pipes inside the walls.

\section{Experimental Methods And Results}

For analysis of the efficiency of the proposed passive cooling of houses and buildings, we need to know first the average temperature changes of the ambient. In Table 1, statistical data of the temperatures in four periods of the year are given for UAE [14]. On figure 1, the average day temperature in UAE during summer is shown. We are more interested in the summer period, because in that period the energy savings are the largest in comparison to spending on air-conditioning.

Table 1. Statistics of temperatures in four periods of the year in UAE [14].

\begin{tabular}{|l|l|l|l|l|}
\hline \multirow{2}{*}{ Period } & Description & \multicolumn{3}{|c|}{ Temperature $\left({ }^{0} \mathrm{C}\right)$} \\
\cline { 3 - 5 } & & Mean daily minimum & Mean daily average & Mean daily maximum \\
\hline 1 Nov-15 Feb & Cool dry & 15 & 21 & 25 \\
\hline 16 Feb - 31 May & Hot dry & 17 & 25 & 35 \\
\hline 1 June -15 Aug & Hot humid & 27 & 33 & 40 \\
\hline 16 Aug - 31 Oct & Cool humid & 23 & 27 & 36 \\
\hline
\end{tabular}

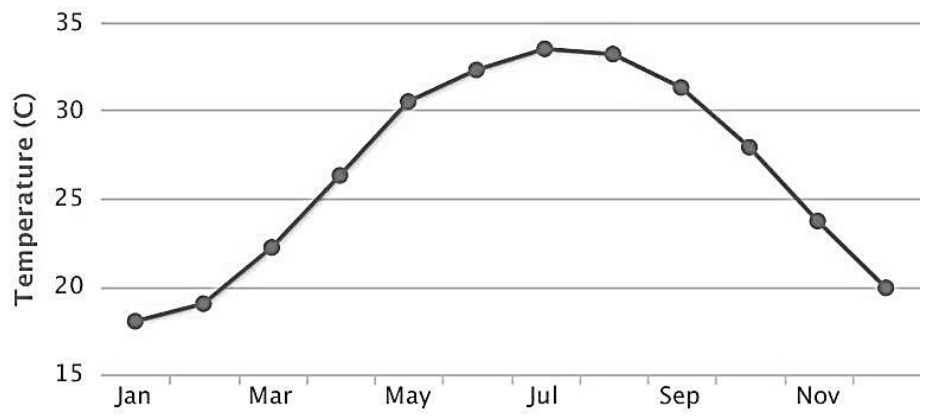

Fig.3. Average day temperature in UAE.

The proposed passive cooling of houses and buildings can be effective only if the building materials have desired properties, such as:

- Insulation materials for the outside walls with low coefficients of thermal conduction in $\mathrm{W} /(\mathrm{m} \cdot \mathrm{K})$ and higher specific heat capacity in $\mathrm{J} /(\mathrm{kg} \cdot \mathrm{K})$;

- Good thermal conduction of the inside walls with high coefficients of thermal conduction and smaller specific heat capacity;

- $\quad$ Lower density of the materials.

The temperature of the incoming municipality water is the most important precondition to have for greater efficiency of the cooling system proposed. This temperature must be lower than the ambient temperature as longer as possible in the daily operation. In summer, this can be easily achieved, for example in Belgium, where the average underground municipality water at depth of $3 \mathrm{~m}$ is $13{ }^{\circ} \mathrm{C}$. In the study, we measured the temperature of the municipality water that comes from depth of $2 \mathrm{~m}$ below the ground and found it $23{ }^{\circ} \mathrm{C}$ in middle of the summer. This is more than enough to consider the proposed passive cooling of houses in UAE as effective and efficient, having on mind that the average ambient temperature during the summer is $33{ }^{\circ} \mathrm{C}$.

After observation of the climate and statistical data related to the UAE energy consumption, and especially after construction and observation of operation of the model house based on water circulation throughout installation placed inside the walls, we were able to propose the following:

- The underground municipality water is cold enough to be considered as effective cooling agent of houses and buildings.

- The passive cooling method based on running the water through installations sandwiched in the walls is energy efficient.

- Energy savings on annual and national level can reach more than half a billion dirhams.

- The proposed passive cooling method is cheap. 
- The proposed method of houses and buildings cooling can work even with greater efficiency in moderate climate regions (Europe, far Asia, North America, Australia, South Africa, etc.).

In order to prove the propositions from above, experimentation on model house has been made reaching the following objectives:

To find by measurements if the average temperature of the municipality water is below $24{ }^{0} \mathrm{C}$, which determines the method of passive cooling effective.

- To construct a model house and put the running water in the walls in a sandwich like structures and measure the indoor air temperature.

- Materials to be used for the model house to be found with similar thermal properties as the real building materials.

- To measure the dynamics of the indoor temperature distribution after water running and check how fast comfortable temperature of $23{ }^{\circ} \mathrm{C}$ can be reached.

- To simulate the energy efficiency of the proposed method of passive cooling of houses and building by use of the municipality water.

\subsection{MATERIALS}

The walls of the model house were prepared from acrylic glass (plexiglass, Poly (methyl methacrylate) PMMA). The dimensions of the walls are $100 \mathrm{~cm} \times 70 \mathrm{~cm}$ (figure 2).

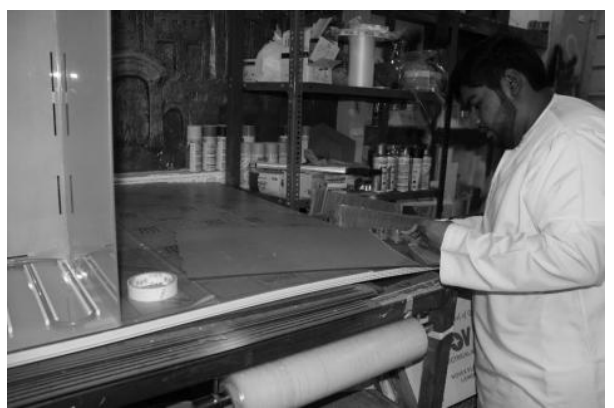

Fig.2. The acrylic glass walls' plates.

Before, draws of the wall with dimensions have been prepared in CorelDRAW (figure 3). The drawing file was uploaded to a laser machine type "Bai Sheng Laser", China, and properly cut (figure 4).

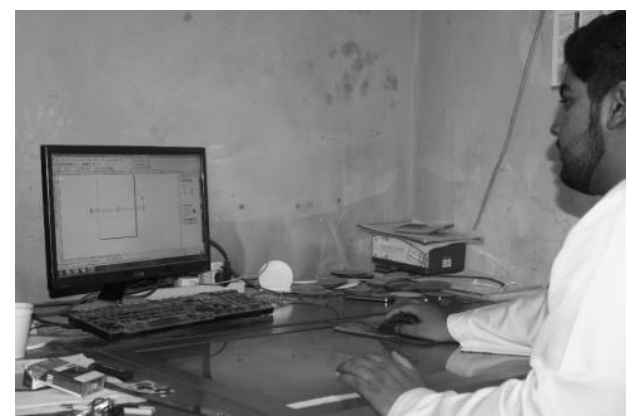

Fig.3. Corel DRAW drawing of the walls.
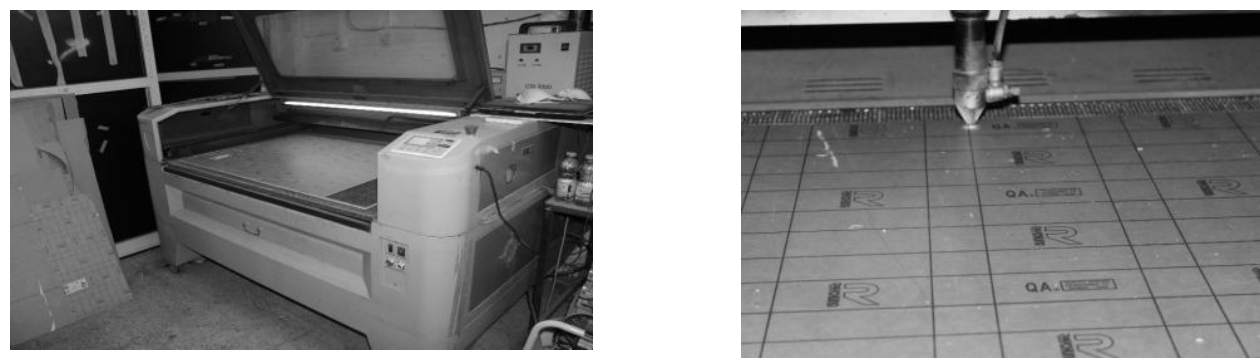

Fig.4. The cutting process 
The walls were glued with an acrylic glue (figure 5). The walls were double sided with gap of $2 \mathrm{~cm}$. Two sides of the model house we filled with desert sand, and the other two were filled with plastic tubes with diameter of $10 \mathrm{~mm}$. One wall of these two have been left transparent for demonstrational purpose. The tubes have been put on plastic straight rails and the curvature of the water tubes at the edges of the walls have been carefully fixed to avoid stacking of the tube that can resist the water flow (fig.6).
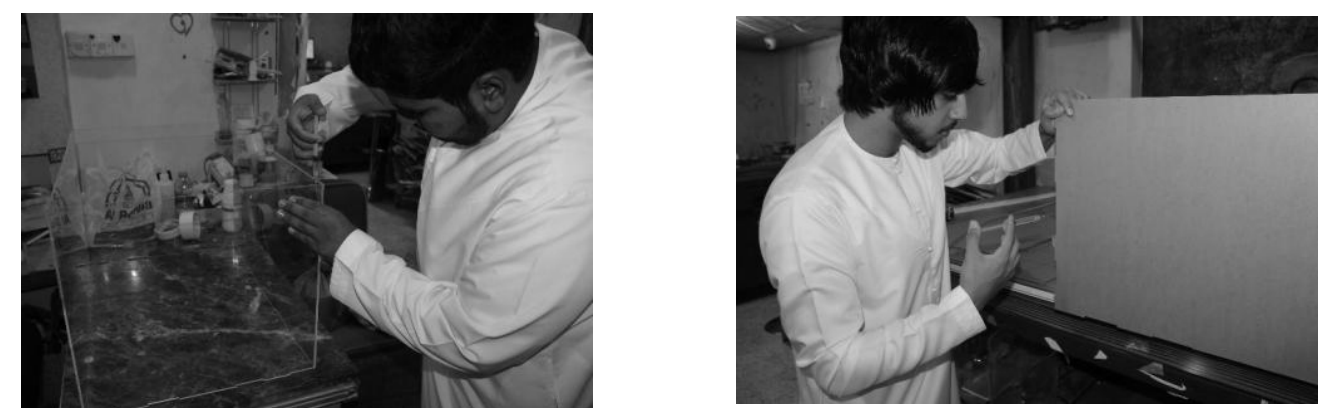

Fig.5. The walls glued.

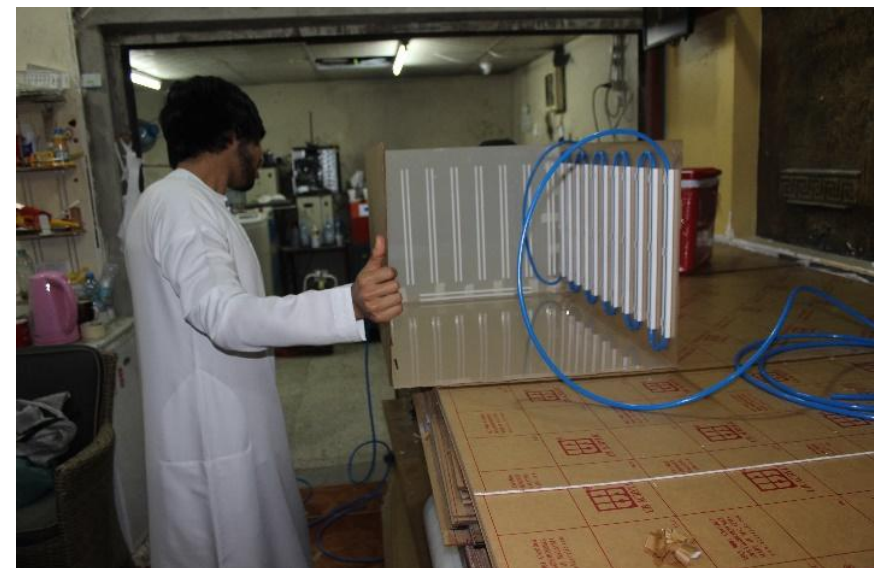

Fig.6. The rails for the plastic water tubes inside the walls.

The transparent wall was filled with gel (hair dressing gel) to simulate building material that is thermally conductive. The gel used as wall filler for one wall (simulation of a thermally conductive building material) and desert sand for the other walls without running water tubes inside. On figure 7, the Adobe Photoshop design of the façade of the model house is shown. We used a traditional Emirate house façade. Working this way, we wanted to give a cultural identity of our project (model house in full display, figure 8).

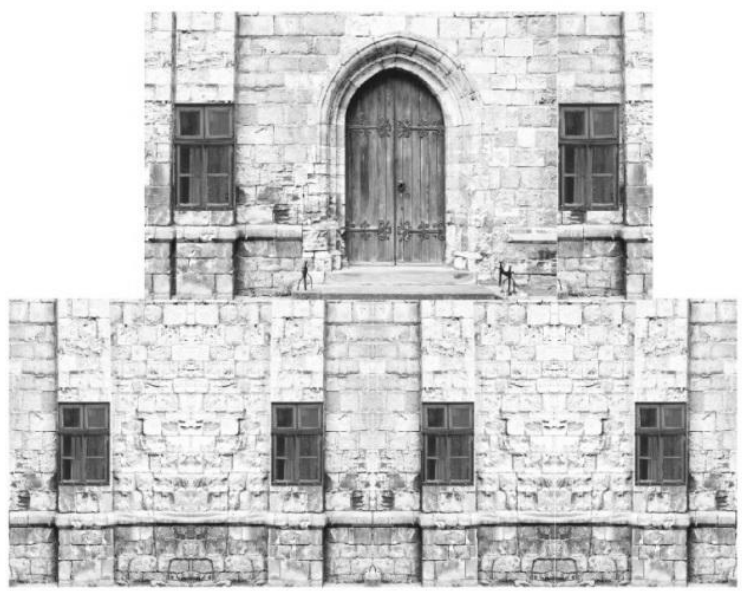

Fig.7. The Emirate style of the model house façade. 


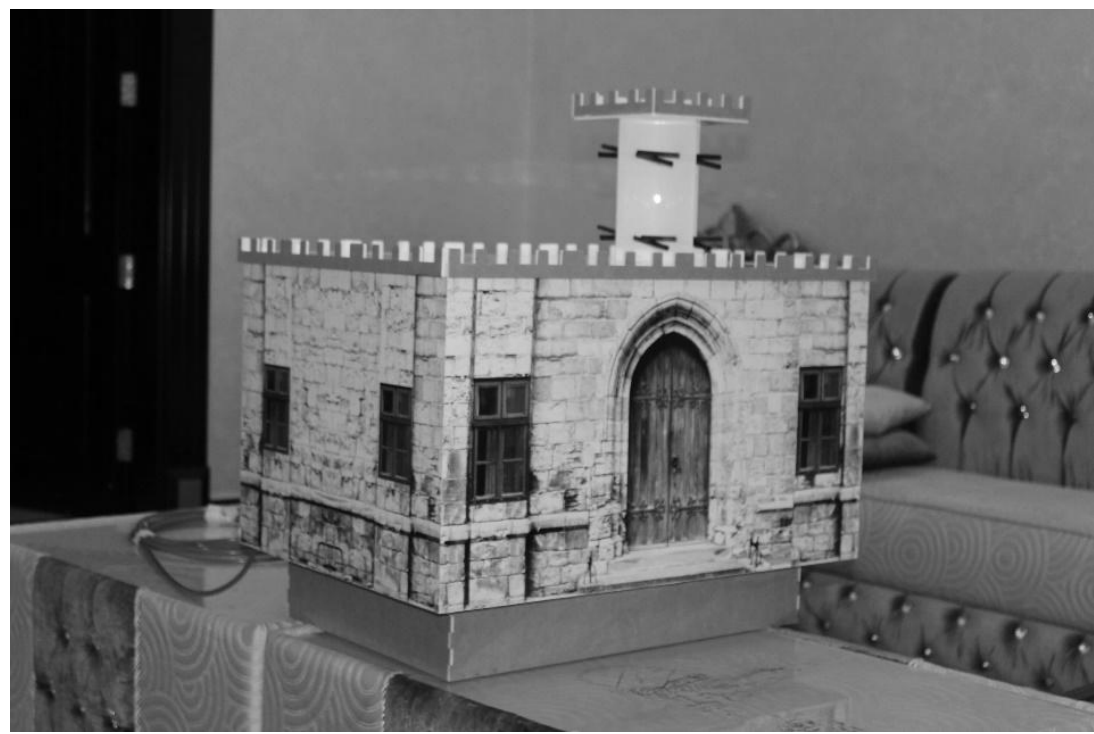

Fig.8. A look of the model house.

For the measurement of the cooling properties of the walls, we used integrated circuit temperature sensor connected to power supply of $5 \mathrm{~V} \mathrm{DC}$ (figure 9), ice cubes-water basket to simulate the cooler municipality water that will go in circulation inside the walls with the help of small 12 Watt pump (figure 10). The temperature measurements were taken on a digital multimeter. The sensitivity of the temperature sensor is very high, $10 \mathrm{mV} /{ }^{0} \mathrm{C}$. We used six temperature sensors to measure the distribution of the temperature on the time of water running: one positioned at $5 \mathrm{~cm}$ from the bottom tightly on the wall with water tubes and another at the top $5 \mathrm{~cm}$ bellow the roof; the third and the forth at the bottom and top position, but at the middle of the model house; the fifth and the sixth on the opposite wall (at bottom and top) where there are no water tubes inside.
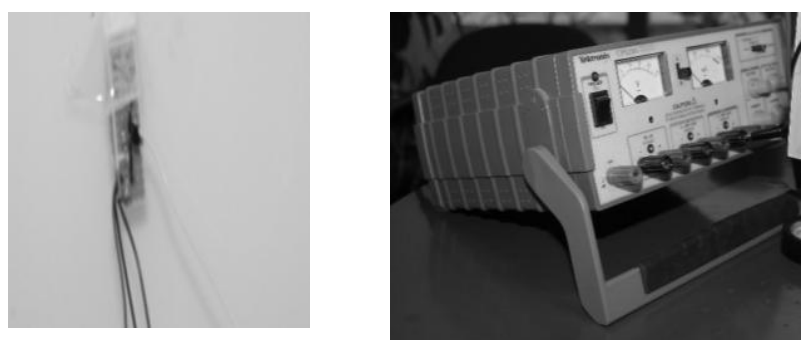

Fig.9. The temperature sensor and power supply.
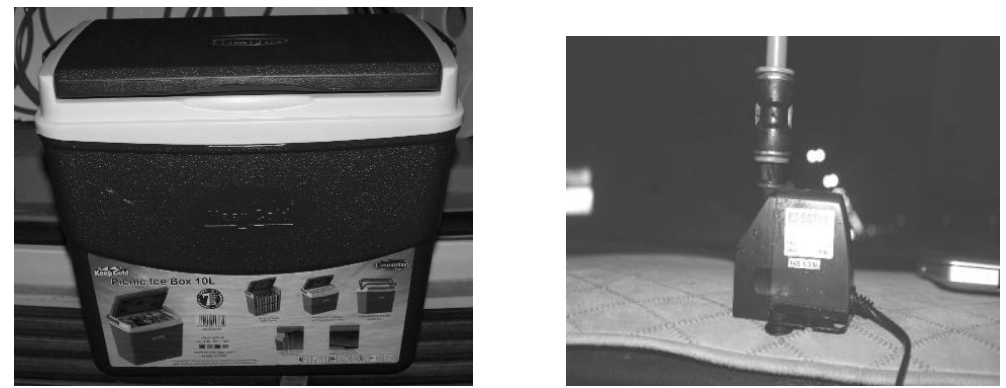

Fig.10. The cold-water basket and the pump.

The full look of the model house under water circulation and temperature measurement conditions is shown on figure 11. 


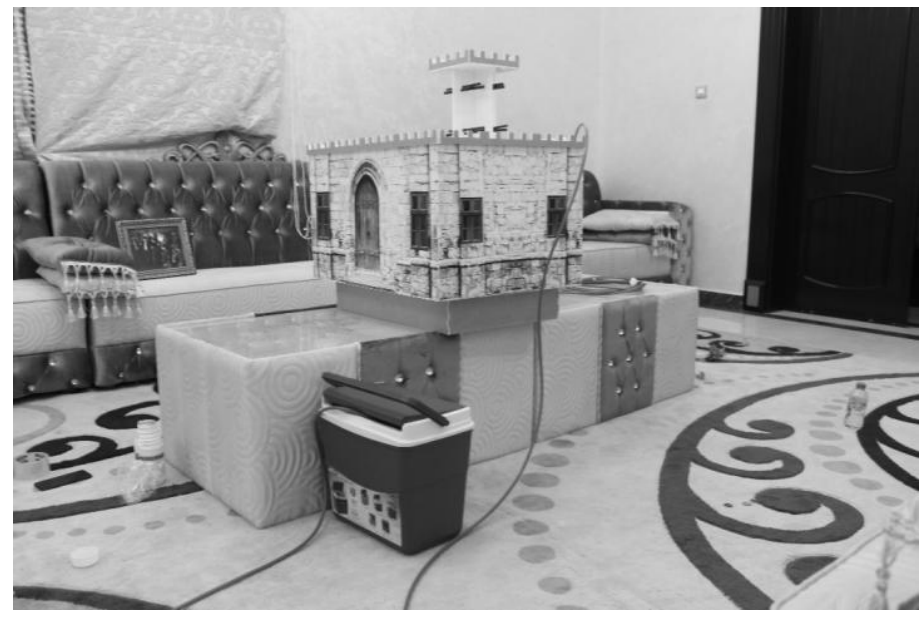

Fig.11. A look on the model house under operation.

\subsection{DATA ANALYSIS}

Simulating municipality underground cool water by using an ice-water basket with small pump proved to be very cheap and effective. We used 6-7 liters water mixed with 1.5 liters ice cubes from the domestic freezer and the mixture gave running water at temperature of $8{ }^{\circ} \mathrm{C}$ for period of two hours. The temperature distribution inside the model house has been followed graphically during cooling with water running through two of the walls. The graph on figure 12 has been created in the OriginPro graphical analysis software. Interpolation of the data to extended time intervals has been done by using appropriate tools in the same software.

The dynamics of the change of the temperature distribution has been analyzed, also, by monitoring the temperatures on every 5 minutes. Energy savings were analyzed on the basis of spared consumption of electricity (in $\mathrm{kW} \cdot \mathrm{h}$ ) needed for running the AC (Table 2). The municipality water, when running through the installation inside the walls, does not need pump (zero energy consumption) to the contrary of the small pump we used for the model house where the pump is needed because the water pressure is small and there are no taps, baths, toilets, kitchen, garden hoses, etc.

Energy saving analysis is summarized in Table 2. The method of collecting data has been based on personal observation and time monitoring of water usage in a household with three bedrooms (two kids, and two parents). The first column represents an hourly period in 24 hours of a day. The second column represents the outdoor temperature. The third column represents description of water consumption activities in the examined household. The fourth column represents the time of the activities summarized for all members in the household. The fifth column represents the water flow rate in units of L/min. The sixth column represents the time of running the air conditioners in the household, as a support to the municipality water cooling. The seventh column represents the time of air conditioners working to provide ambient cooling to $23{ }^{0} \mathrm{C}$, in case when there is no municipality running water at all. The eight column represents the results from the calculation of the energy savings in $\mathrm{kWh}$ from the cooling effects of the municipality water. The results are shown in pair of the savings related for the two cases: air conditioner support and only the air conditioner running.

Table 2. Energy savings simulation in an average household. Outside maximum temperature of $36{ }^{\circ} \mathrm{C}$, minimum temperature of $22{ }^{0} \mathrm{C}$. Incoming average water temperature of $21{ }^{\circ} \mathrm{C}$.

\begin{tabular}{|c|c|c|c|c|c|c|c|}
\hline $\begin{array}{l}\text { Time } \\
\text { period }\end{array}$ & $\begin{array}{l}\text { Outdoor } \\
\text { temp. } \\
\left({ }^{0} \mathrm{C}\right)\end{array}$ & $\begin{array}{l}\text { Description of water } \\
\text { consumption activities }\end{array}$ & $\begin{array}{l}\text { Time } \\
\text { (min.) }\end{array}$ & $\begin{array}{l}\text { Water } \\
\text { flow } \\
\text { rate } \\
(\mathrm{L} / \mathrm{min}) \\
\end{array}$ & $\begin{array}{l}\text { Air } \\
\text { conditioner } \\
\text { Support } \\
\text { (min.) } \\
\end{array}$ & $\begin{array}{l}\text { Air } \\
\text { conditioner } \\
\text { only (min.) }\end{array}$ & $\begin{array}{l}\text { Results from } \\
\text { simulation of the } \\
\text { energy savings } \\
(\mathrm{kWh})\end{array}$ \\
\hline 1 & 24 & $\mathrm{WC}+$ bath & 25 & 5 & 0 & 6 & $1.2 / 0$ \\
\hline 2 & 23.5 & WC & 5 & 3 & 0 & 5 & $1.0 / 0$ \\
\hline 3 & 23 & - & - & - & 0 & 0 & $0 / 0$ \\
\hline 4 & 23.5 & - & - & - & 0 & 0 & $0 / 0$ \\
\hline 5 & 23.5 & $\mathrm{WC}$ & 5 & 3 & 0 & 0 & $0 / 0$ \\
\hline 6 & 24 & WC + bath & 35 & 8 & 0 & 5 & $1.0 / 0$ \\
\hline 7 & 24.5 & Kitchen & 20 & 5 & 0 & 6 & $1.2 / 1.2$ \\
\hline 8 & 25 & Kitchen & 30 & 5 & 0 & 7 & $1.4 / 0$ \\
\hline 9 & 26 & - & - & - & 3 & 8 & $1.6 / 0.6$ \\
\hline 10 & 27.5 & House cleaning & 25 & 8 & 0 & 8 & $1.6 / 0$ \\
\hline 11 & 30 & House cleaning $+\mathrm{WC}$ & 35 & 8 & 0 & 9 & $1.8 / 0$ \\
\hline 12 & 32 & Kitchen & 35 & 5 & 0 & 10 & $2.0 / 0$ \\
\hline 13 & 34.5 & Kitchen & 25 & 3 & 5 & 10 & $2.0 / 1.0$ \\
\hline 14 & 36 & WC + house cleaning & 15 & 8 & 5 & 11 & $2.2 / 1.0$ \\
\hline
\end{tabular}


Passive cooling of houses by placing the municipality running water installation inside the walls

\begin{tabular}{|l|l|l|l|l|l|l|l|}
\hline 15 & 35.5 & - & - & - & 10 & 12 & $2.4 / 2.0$ \\
\hline 16 & 34 & Kitchen & 15 & 8 & 6 & 10 & $2.0 / 1.2$ \\
\hline 17 & 32.5 & Lunch & 40 & 5 & 0 & 10 & $2.0 / 0$ \\
\hline 18 & 30 & WC + Kitchen & 30 & 8 & 0 & 10 & $2.0 / 0$ \\
\hline 19 & 29 & - & - & - & 5 & 9 & $1.8 / 1.0$ \\
\hline 20 & 28.5 & WC & 10 & 10 & 3 & 9 & $1.8 / 0.6$ \\
\hline 21 & 28 & Bath & 15 & 10 & 0 & 9 & $1.8 / 0$ \\
\hline 22 & 27 & WC & 15 & 5 & 0 & 7 & $1.4 / 0$ \\
\hline 23 & 26 & Bath & 20 & 8 & 0 & 5 & $1.0 / 0$ \\
\hline 24 & 25 & WC & 20 & 5 & 0 & 3 & $0.6 / 0$ \\
\hline
\end{tabular}

The results from the measurement of the temperature at six different positions inside the model house in time interval of 70 minutes are shown in Table 3.

Table 3. The dynamics of temperature changes at the position of the six sensors (1 - bottom/ water wall; 2 top/water wall; 3 - bottom/middle house; 4 - top/middle house; 5 - bottom/ water empty wall; 6 - top/water empty wall).

\begin{tabular}{c|c|c|c|c|c|c}
\hline 1 & 2 & 3 & 4 & 5 & 6 & time $(\mathrm{min})$ \\
\hline 0.0 & 0.0 & 0.0 & 0.7 & 0.0 & 0.0 & 0 \\
\hline-1.4 & -0.2 & -0.2 & 0.5 & -0.5 & -0.4 & 5 \\
\hline-2.6 & -0.4 & -0.4 & 0.3 & -0.9 & -0.5 & 10 \\
\hline-3.4 & -0.6 & -0.7 & 0.1 & -1.1 & -0.6 & 15 \\
\hline-3.8 & -0.9 & -0.8 & -0.2 & -1.4 & -0.8 & 20 \\
\hline-4.2 & -1.2 & -1.1 & -0.5 & -1.7 & -1.0 & 25 \\
\hline-4.6 & -1.5 & -1.4 & -0.8 & -2.0 & -1.4 & 30 \\
\hline-4.8 & -1.7 & -1.6 & -1.0 & -2.3 & -1.6 & 35 \\
\hline-5.1 & -1.9 & -1.8 & -1.2 & -2.5 & -1.7 & 40 \\
\hline-5.4 & -2.2 & -2.0 & -1.5 & -2.6 & -1.9 & 45 \\
\hline-5.6 & -2.4 & -2.3 & -1.7 & -2.9 & -2.2 & 50 \\
\hline-5.9 & -2.5 & -2.5 & -1.8 & -3.2 & -2.4 & 55 \\
\hline-6.1 & -2.7 & -2.6 & -2.0 & -3.4 & -2.6 & 60 \\
\hline-6.2 & -2.9 & -2.9 & -2.2 & -3.6 & -2.7 & 65 \\
\hline-6.3 & -3.0 & -3.0 & -2.3 & -3.7 & -2.9 & 70 \\
\hline
\end{tabular}

The temperature distribution of the indoor ambient in the model house depends on time passed after the start of the cooling process (Table 3, figure 12). Sensors 1 and 2 are closer to the cooled walls and the temperature there drops significantly (around $\left.5{ }^{\circ} \mathrm{C}\right)$ in the first half an hour, and for the furthest sensors $(5$ and 6$)$ drops only for $1-2{ }^{\circ} \mathrm{C}$. This was expected, because the thermal mass of the ambient air is low, the thermal conductance of the air is low also, and the convection of the indoor air is slow due to large dimension of the model house. If the dimensions of the room in the model house are scaled to real dimensions of a room in a house (celling at $3.50 \mathrm{~m}$ ), the room would be with width of $7 \mathrm{~m}$, which is above the average width of a real room. The dynamics of the change of the temperature distribution is fast. We found that after 60 minutes, sensors 2, 3, 4, 5 and 6 showed stable drop of the ambient temperature, while sensor 1 showed maximum drop of $6.0{ }^{\circ} \mathrm{C}$ (fig.12). This is a quite homogenous distribution for short time period that makes the ambient more comfortable for living or working.

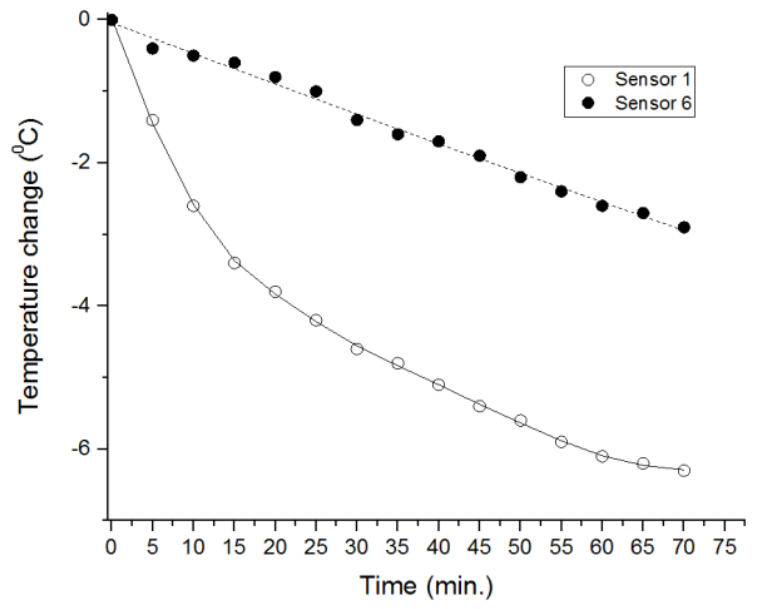

Fig.12. Graphical dependence of the indoor temperature distribution of the model house. 
It is obvious from fig. 12 that the rate of temperature drop is bigger closer to the wall in which water is circulating (sensor 1). The rate of temperature change is smaller at sensor 6 , which is a sensor positioned closer to the wall in which water is not circulating (opposite side). However, it can be predicted by interpolation to 2.5 hours passed, that the temperature drop there will be greater than $6{ }^{0} \mathrm{C}$, which is acceptable, if the ambient temperature was $29-30{ }^{\circ} \mathrm{C}$ (drop to $23{ }^{\circ} \mathrm{C}$, the most affordable ambient temperature).

Another behavior of passive cooling is noticeable from analysis of data given on fig.12. The drop of temperature at sensor 1 (positioned closer to the cooling wall) is going at smaller and smaller rate as the time is passing. This behavior has been expected. After 2.5 hours, there is no significant change of the ambient temperature, because of the steady case of heat exchange between the cooling wall and the air from the house. This case is known as thermal equilibrium. From analysis on the data in Table 2, we found that the actual power consumption, including the savings is $7.6 \mathrm{kWh}$ for 24 hours. Without water running inside the walls it is 32.8 $\mathrm{Kwh}$. The difference is not insignificant from the practical point of view.

Electricity tariff of FEWA, the producer and supplier of electrical energy in UAE, is given in Table 3. Taking into account the annual average savings on electricity from cooling the walls, and after comparing the prices for different consumption categories, it is obvious that the greatest savings on money can be achieved in residential and commercial entities. In UAE, the number of residential and commercial entities are in huge extent greater than the agricultural or the governmental entities for which the tariff is smaller [14]. This indicates that the money savings can be greater for households and commercial entities:

Total Savings $($ residential $)=25 \mathrm{kWh}$ (daily savings on consumption per housing unit) $\mathrm{x} 0.30$ aed $\mathrm{x} 500,000$ units $=675$ million aed

Total Savings $($ commercial $)=7.5 \mathrm{kWh}$ (savings on consumption per housing unit $) \times 0.30$ aed $\times 200,000$ units $=$ 81 million aed.

\section{Total predicted annual money savings $=756$ million aed .}

In the above calculations, the daily savings are counted for the summer period. Winter is taken as period without need for savings, and at spring and autumn the daily savings are taken at half value from the summer, because of the lower ambient average temperature in comparison to the summer.

\section{Conclusion}

The method of passive cooling of houses and buildings by placing the running water installation inside the walls gives promising results that can make it useful in practice. The energy savings are affordable and the cost-benefit analysis shows that the return on investment is favorable in five years. UAE has a climate and the municipality water is cold enough to consider the proposed method of cooling houses and buildings as affordable for construction in future.

\section{Acknowledgements}

We acknowledge Mohammed Arafat Muter for giving us the opportunity to work in his workshop on Corniche in Ras al Khaimah on designing and constructing the model house and the water running installation inside the house's walls.

We acknowledge Emirates Foundation for giving us funds to realize the research.

[1]. The State of the World Cities. UN-HABITAT, 2001.

\section{References}

[2]. H. Akbari, S. Davis, S. Dorsano, J. Huang, S. Winnett, Cooling our communities. A guidebook on tree planting and light-colored surfacing, in: US Environmental Protection Agency (New York, Office of Policy Analysis, 2009).

[3]. Y.C. Sezgin, M. Celik, The Use of Municipality Water System for Building Cooling as an Alternative to Conventional Ground Source Heat Pump, Progress in Clean Energy, 1, 2015, 121-133.

[4]. B. Givoni, Indoor Temperature Reduction by Passive Cooling Systems, Solar Energy, 85, 2011, 1692-1726

[5]. A. Gilbert, S. Cairncross, J.E. Hardoy, D. Satterthwaite, The poor die young: housing and health in third world cities, The Geographical Journal, 158 (2), 1990, 234.

[6]. M. Maerefat, A.P. Haghighi, Natural cooling of stand-alone houses using solar chimney and evaporative cooling cavity, Renewable Energy, 35, 2010, 2040-2052.

[7]. S.M. Jafarian, S.M. Jaafarian, P. Haseli, M. Taheri, Performance analysis of a passive cooling system using underground channel (Naghb), Energy and Buildings, 42, 2010, 559-562.

[8]. http://data.worldbank.org/country/united-arab-emirates. Retrieved on February 12, 2017.

[9]. C. Cartalis, A. Synodinou, M. Proedrou, A. Tsangrassoulis, M. Santamouris, Modifications in energy demand in urban areas as a result of climate changes: an assessment for the southeast Mediterranean region, Energy Conversion and Management 42 (14), 2001, 1647-1656.

[10]. M. Santamouris, Heat island research in Europe: the state of the art, Advances in Building Energy Research, 1(1), 2007, 123-150. 
[11]. M. Antinucci, D. Asiain, B. Fleury, J. Lopez, E. Maldonado, M. Santamouris, A. Tombazis, S. Yannas, Passive and hybrid cooling of buildings - state of the art, International Journal of Solar Energy, 11 (3-4), 1992, 251-271.

[12]. J. Hardoy, D. Mitlin, D. Satterthwaite, Environmental problems in an urbanizing world, Earthscan, 19 (2), $2001,188$.

[13]. www.ncms.ae/en. Retrived on October 1, 2016

[14]. http://fcsa.gov.ae/en-us. Retrieved on November 23, 2016. 